\title{
Locoregional recurrence of Frantz' tumor: a case report and review of the literature
}

Ana lamada Pereira Prata, MD ${ }^{1}$

Gustavo Gomes Mendes, MD ${ }^{1}$

Rubens Chojniak, PhD, MD ${ }^{1}$

1. Imaging Department, A.C.Camargo Cancer Center, São Paulo, Brasil

\section{SUMMARY}

Frantz' tumours or solid pseudopapillary tumours of the pancreas are rare neoplasms with low malignant potential. Young women in the second to third decades of life are more frequently affected. The treatment of choice is resection of the lesion, which is often curative. The recurrence is uncommon when radical surgical resection is used. Radiological characteristics are important for the correct diagnosis, since the preoperative planning is fundamental to obtain the cure. The objective of this study is to report a rare case of locoregional recurrence and to review the radiological findings of solid pseudopapillary tumours of the pancreas in the literature, as well to know the incidence and risk factors of tumor recurrence. This case report is from a 37-year-old female patient evaluated at an Oncologic Hospital, in the city of São Paulo, Brazil, who presented an uncommon evolution of the disease, characterized by local recurrence despite the complete resection of the primary lesion with free margins.

KEYWORDS: Pancreatic neoplasms. Recurrence. Magnetic resonance imaging.

\section{INTRODUCTION}

Frantz tumours or solid pseudopapillary tumours (SPTs) of the pancreas are rare. It is estimated that they correspond to $0.3 \%$ to $2.7 \%$ of all pancreatic tumors. ${ }^{1,2}$ Recently there has been an increase in its incidence, which may be related to the greater use of immunohistochemical methods. ${ }^{3}$ There are several eponyms to denominate SPTs, such as: Hamoudi Tumor, Frantz Tumor and others. However, according to the World Health Organization (WHO) classification, the most appropriate nomenclature is solid pseudopapillary tumor of the pancreas. ${ }^{4}$
They are tumours of low malignant potential, which predominate in young women in the second to third decades of life. ${ }^{5,6}$

Complete surgical resection is the curative treatment. ${ }^{7,8}$ SPTs are usually limited to the pancreas, allowing the resection of the entire lesion. Locoregional recurrence is estimated to occur in less than $10 \%$ to $15 \%$ of surgical resections. ${ }^{9}$ Some factors are related to an increased risk of recurrence, such as lymphatic and vascular invasion, synchronic metastasis, and invasion of the tumor capsule. ${ }^{10}$ In these 
cases, a more careful approach to long-term follow-up is needed. ${ }^{7}$

In the imaging service of this oncology reference hospital, located in the city of São Paulo, we evidenced a case of recurrence of an SPT of the pancreas submitted to complete resection of the lesion with free margins. This is a case report obtained from imaging studies conducted in May 2015, before resection of the primary lesion, and in September 2017, after surgery, showing a new lesion.

Considering that SPT is a rare neoplasm, and that recurrence after free-margin resection is uncommon, we report this case with the purpose of reviewing the radiological findings of SPT in the literature, as well as knowing the incidence and risk factors of tumor recurrence.

\section{CASE REPORT}

GPSC, a 37-year-old Brazilian female was referred to the imaging department for pancreatic mass screening visualized in an imaging study from another hospital.

Initial nuclear magnetic resonance imaging (MRI) performed at the oncology centre in May 2015 included T1-weighted and T2-weighted images, intravenous paramagnetic contrast injection, fat saturation and diffusion sequences. It was characterized the increase of head/uncinate pancreas process at the expense of a mass, with a heterogeneous solid-cystic aspect, predominating hyposignal in $\mathrm{T} 1$, hypersignal in $\mathrm{T} 2$ and contrast enhanced, measuring $35 \times 25 \mathrm{~mm}$
(Figure 1). Such lesion had intimate contact with the proximal portion of the portal vein and spleno-mesenteric junction. No lymphadenopathy or dilatation of the intra- and extrahepatic bile ducts were observed. The remaining pancreatic parenchyma did not show significant changes.

Ultrasound-guided fine needle puncture (Paaf) was performed, which revealed findings compatible with SPT. The patient underwent complete resection of the lesion, with gastroduodenopancreatectomy and lymphadenectomy. Anatomopathological examination confirmed the presence of an SPT. Surgical margins and lymph nodes were free of neoplastic involvement. Immunohistochemical analysis was compatible with SPT.

After two years, another MRI study, performed with the same protocol as the previous examination, a solid, heterogeneous mass was identified with variable signal in $\mathrm{T} 2$, intermediate signal in $\mathrm{T} 1$, heterogeneous post-contrast enhancement, peripheral and with a tendency to homogenization in the late phases, located in the topography of the head/uncinate process of the pancreas, measuring $44 \times 31 \mathrm{~mm}$ (Figure 2). This lesion showed proximity to the inferior vena cava and inferior mesenteric vein, but without signs of vascular invasion. The pancreatic duct had dimensions at the upper limit of normality. In view of the appearance of a new lesion after complete resection of the primary lesion, the possibility of tumor recurrence was considered, which was later confirmed by anatomopathological examination.

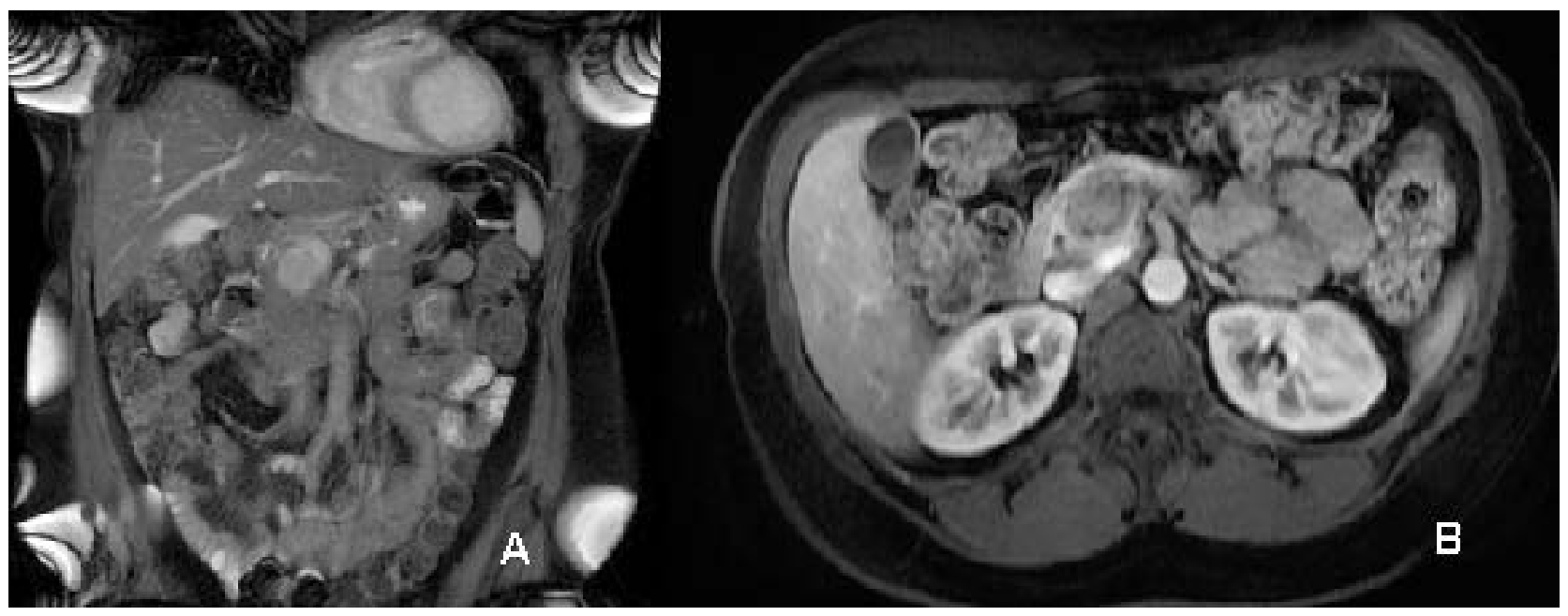

FIGURE 1. 2015 MRI. Coronal section, T2-weighted, shows solid-cystic lesion, with hypersignal in T2, well delimited, in the head/ uncinate process of the pancreas (A). Axial cut, T1-weighted after contrast, characterizing heterogeneous post-contrast enhancement (B). 


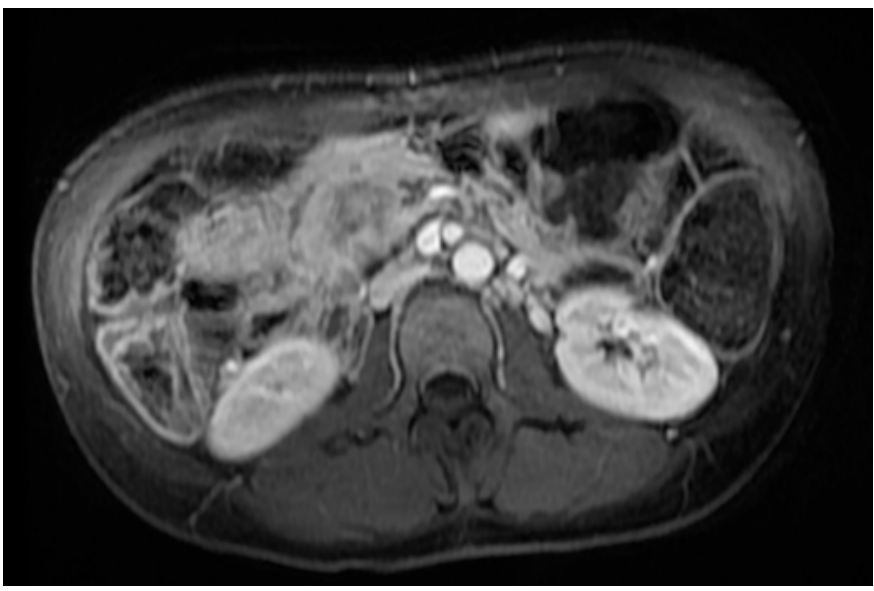

FIGURE 2. 2017 MRI. Axial cut, T1-weighted after contrast, showing a new solid and heterogeneous lesion, with peripheral post-contrast enhancement and with tendency to homogenization in the late phases, on topography of the head/uncinate process of the pancreas.

\section{DISCUSSION}

Most SPTs are benign. It is estimated that $10 \%$ to $15 \%$ are malignant. ${ }^{11}$ Recurrence is related to signs of aggressive behaviour, characterized by: lymphatic and vascular invasion, synchronic metastasis and invasion of the tumor capsule. ${ }^{10}$ Some studies suggest that tumours with a larger to $5 \mathrm{~cm}$ in diameter have greater malignant potential and risk of higher recurrence. ${ }^{11}$ The high mitotic rate and nuclear atypia were also related to aggressive behavior ${ }^{4}$. Although these signs are related to the greater risk of relapse, their absence does not exclude the possibility that recurrence occurs in the long term. The most common sites of metastases are liver, portal vein, spleen, regional lymph nodes, omentum and peritoneum.,

The diagnostic hypothesis is usually made through imaging tests, since the clinical status is nonspecific. Patients may be asymptomatic, report vague abdominal discomfort or symptoms related to the compression of adjacent structures by the tumor. ${ }^{6}$
SPTs have variable presentations on imaging tests. They are more common in the pancreatic tail and head.,5 Generally, they are large, well-circumscribed, heterogeneous, solid-cystic masses at the expense of varying amounts of necrosis, haemorrhage, and cystic areas. ${ }^{5}$ Calcifications may be present. ${ }^{12}$ The solid component shows heterogeneous and progressive contrast enhancement. Dilatation of the biliary tract is rare ${ }^{12}$. MRI provides more information than computed tomography on the resectability and internal characteristics of the lesion, facilitating the identification of purely solid tumours and with smaller dimensions. ${ }^{13}$

Complete surgical resection is the most efficient treatment, even in the presence of metastases or vascular invasion, and should be done for the primary lesion and for metastases if present. ${ }^{7}$ Less than $10 \%$ to $15 \%$ of resections are estimated to evolve with recurrence. ${ }^{9}$ In patients with signs of aggression, more careful follow-up is recommended, since recurrences may occur after five years of surgery. ${ }^{7}$ In cases of relapse, surgical resection is also the most efficient treatment. ${ }^{6,7}$

SPTs present a favourable prognosis, even when there are metastases, invasion or local recurrence. ${ }^{7}$ In such cases, surgery is not a contraindication. ${ }^{8}$

The case report refers to a patient with epidemiological and imaging characteristics compatible with SPT. An ultrasound-guided Paaf was used to distinguish neoplasm from other pancreatic tumours, allowing preoperative planning, since lesion resection is often curative. Despite this, the patient evolved with relapse after two years of surgery.

SPT is a rare neoplasm with few cases of relapse after complete surgical resection. The importance of this case report lies in the correct diagnosis, since resection of the lesion is associated with long-term survival.

\section{RESUMO}

Os tumores de Frantz ou tumores pseudopapilares sólidos do pâncreas são neoplasias raras, que apresentam baixo potencial maligno. A maioria acomete mulheres jovens na segunda a terceira década de vida. O tratamento de escolha é a ressecção da lesão, uma vez que é frequentemente curativa. A recidiva é incomum quando é empregada ressecção cirúrgica completa. As características radiológicas são importantes para a hipótese diagnóstica, uma vez que o planejamento pré-operatório é fundamental para a obtenção da cura. O presente estudo tem como objetivo relatar um caso raro de recidiva locorregional e rever na literatura os achados radiológicos dos tumores pseudopapilares sólidos do pâncreas, assim como conhecer a incidência e os fatores de risco da recorrência tumoral. Este relato de caso é de uma paciente do sexo feminino, de 37 anos, avaliada em um hospital de referência oncológica, na cidade de São Paulo, Brasil, que apresentou uma evolução incomum da doença, caracterizada pela recorrência locorregional, apesar da ressecção da lesão primária com margens livres. 


\section{REFERENCES}

1. Crawford BE $2^{\text {nd }}$. Solid and papillary epithelial neoplasm of the pancreas, diagnosis by cytology. South Med J. 1998;91(10):973-7.

2. Lam KY, Lo CY, Fan ST. Pancreatic solid-cystic-papillary tumor: clinicopathologic features in eight patients from Hong Kong and review of the literature. World J Surg. 1999;23(10):1045-50.

3. Santero Ramírez MP, Gonzalvo E, Martínez A, del Río Marco F). Papillary cystic solid tumor of the pancreas. Three different ways of presentation. Rev Esp Enferm Dig. 2004;96(4):285-6.

4. Kloppel G, Solcia E, Longnecker DS, Capella C, Sobin L. Histological typing of tumours of the exocrine pancreas. $2^{\text {nd }}$ ed. Berlin: Springer; 1996.

5. Papavramidis T, Papavramidis S. Solid pseudopapillary tumours of the pancreas: review of 718 patients reported in English literature. I Am Coll Surg. 2005;200(6):965-72.

6. Yu PF, Hu ZH, Wang XB, Guo JM, Cheng XD, Zhang YL, et al. Solid pseudopapillary tumor of the pancreas: a review of 553 cases in Chinese literature. World J Gastroenterol. 2010;16(10):1209-14.

7. El Nakeeb A, Abdel Wahab M, Elkashef WF, Azer M, Kandil T. Solid pseudopapillary tumour of the pancreas: incidence, prognosis and outcome of surgery (single centre experience). Int J Surg. 2013;11(6):447-57.
8. Mao C, Guvendi M, Domenico DR, Kim K, Thomford NR, Howard JM Papillary cystic and solid tumours of the pancreas: a pancreatic embryonic tumor? Studies of three cases and cumulative review of the world's literature. Surgery. 1995;118(5):821-8.

9. Sperti C, Berselli M, Pasquali C, Pastorelli D, Pedrazzoli S. Aggressive behaviour of solid-pseudopapillary tumor of the pancreas in adults: a case report and review of the literature. World J Gastroenterol. 2008;14(6):960-5.

10. Serrano PE, Serra S, Al-Ali H, Gallinger S, Greig PD, McGilvray ID, et al. Risk factors associated with recurrence in patients with solid pseudopapillary tumours of the pancreas. JOP. 2014;15(6):561-8.

11. Kang CM, Kim KS, Choi JS, Kim H, Lee WJ, Kim BR. Solid pseudopapillary tumor of the pancreas suggesting malignant potential. Pancreas. 2006;32(3):276-80

12. Choi JY, Kim MI, Kim JH, Kim SH, Lim IS, Oh YT, et al. Solid pseudopapillary tumor of the pancreas: typical and atypical manifestations. AJR Am J Roentgenol. 2006;187(2):W178-86.

13. Yu MH, Lee JY, Kim MA, Kim SH, Lee JM, Han JK, et al. MR imaging features of small solid pseudopapillary tumours: retrospective differentiation from other small solid pancreatic tumours. AJR Am J Roentgenol. 2010;195(6):1324-32. 